\title{
Exchange Rate Misalignment and Economic Growth: Evidence from Nonlinear Panel Cointegration and Granger Causality Tests
}

\author{
Christian K. Tipoy* \\ Marthinus C. Breitenbach ${ }^{\dagger}$ \\ and \\ Mulatu F. Zerihun ${ }^{\ddagger}$
}

2016

\begin{abstract}
The importance of exchange rate in an economy can be seen in the various policies implemented to manage its level and evolution on a daily basis. A large body of literature has analyzed the impact of exchange rate, or its deviation from certain equilibrium, on economic growth. The correlation between exchange rate undervaluation and economic growth is among the most investigated open macroeconomics topics. However, the question is "does exchange rate undervaluation truly growth enhancing? The purpose of this study is to analyze the impact of exchange rate misalignment on economic growth for a sample of emerging economies from 1970 to 2014 using a panel smooth transition regression (PSTR) vector error correction model. Besides, we provide a Granger causality test conducted in a non-linear framework. We find that a rise in misalignment increases significantly output in the short-run when currencies are close to equilibrium. When they are highly misaligned, the impact on growth is reduced. However, no significant impact of output on misalignment was found in the short-run. We provide evidence that misalignment Granger causes output at any given level of misalignment both in the short and long-run. A weaker Granger causality was found between output and misalignment. This raises some important implications. Although emerging economies can use undervaluation as a growth strategy, the benefits are smaller the larger the undervaluation. There is therefore an incentive to keep exchange rates closer to their equilibrium.
\end{abstract}

Keywords: Exchange Rate Misalignment, Nonlinear Panel Vector Error Correction Model, Cross-sectional Dependence, Granger Causality

JEL Classification: C23,C24,C26,F43

\footnotetext{
${ }^{*}$ PhD Candidate, Department of Economics, University of Pretoria, South Africa. Lecturer, School of Accounting, Economics and Finance, University of KwaZulu-Natal, South Africa. Tel: +27 36078 70. Email: tipoy@ukzn.ac.za

${ }^{\dagger}$ Department of Economics, University of Pretoria, South Africa. Tel: +27 128423437

${ }^{\ddagger}$ Department of Economics, Tshwane University of Technology, South Africa. Tel: +27 123820574 . Email: zerihunmf@tut.ac.za
} 


\section{Introduction}

The correlation between exchange rate undervaluation and economic growth is among the most investigated open macroeconomics topics. This has been exacerbated by the large accumulation of foreign reserves, especially by East-Asian economies, following the 1997 crisis; and their relationship to global imbalance, financial stability and export competitiveness (Dooley et al., 2003; Aizenman and Lee, 2007) ${ }^{1}$. Soon, capital control and exchange rate undervaluation became powerful strategies for growth for China and other emerging economies (Dooley et al., 2003; Aguirre and Calderón, 2005). Exchange rate does matter. Experience shows that governments use a wide rage of instruments such as monetary, fiscal, incomes and capital management policies in order to manage the level and evolution of the real exchange rate (Rapetti, 2013). However, the question is "does exchange rate undervaluation truly growth enhancing?" Before reviewing the different findings, there is first a need of conceptualizing an equilibrium exchange rate (EER) from which undervaluation is computed.

There is a lack of consensus in the definition of EER ${ }^{2}$. However, we borrow from the work of Driver and Westaway (2005) and differentiate between short, medium and long-run EER. The short-run EER is the exchange rate at which fundamental determinants are at their actual values after abstracting from the influence of random shocks. This exchange rate fluctuates following the economy disequilibrium. The medium-run EER is the exchange rate compatible with the economy internal and external balances. The former occurs whenever the economy is at the full employment with low level of inflation and the latter refers to the level of current account that stabilises the external debt. The last concept, the long-run EER, refers to the exchange rate that corresponds to the point at which there is no endogenous tendency for the economy to change. Given these different definitions of EER, two estimation methodologies, besides the purchasing power parity (PPP), stand out: the fundamental equilibrium exchange rate (FEER) and the behavioural equilibrium exchange rate (BEER). The FEER of Williamson (1994) relates to the medium-run EER. It starts by defining the external balance using the equalization of the current account to the capital

\footnotetext{
${ }^{1}$ Aizenman and Lee (2007) find a limited support for the mercantilist approach that links the hoarding of reserves and export competitiveness.

${ }^{2}$ Driver and Westaway (2005) and Siregar (2011) analyse thoroughly the different concepts of equilibrium exchange rates.
} 
account. The FEER hypothesizes that the internal balance will be achieved once the economy is at the external balance. The BEER of MacDonald (1997) and Clark and MacDonald (1998) is more than an empirical approach that relies on the estimation a long-run relationship between some fundamental determinants and a measure of exchange rate, usually the real effective exchange rate (REER). Once the EER is computed, exchange rate misalignment is obtained as the difference between the observed exchange rate and the $\mathrm{EER}^{3}$.

There is a large body of literature that analyses the correlation between exchange rate misalignment and economic growth. One of the early views is based on the "Washington Consensus". 4 According to this view, exchange rate is set at a level such that internal and external balances are maintained. Thus a deviation from this "equilibrium" in form of overvaluation or undervaluation, which is viewed as some sort of macroeconomic disequilibrium, will hamper growth (Williamson, 1994; Berg and Miao, 2010). One of the seminal paper is the work of Rodrik (2008). Using a large sample of developed and developing countries, Rodrik (2008) analyses the impact of undervaluation on economic growth between 1950 and 2004. The misalignments are based on the PPP index approach. He finds that undervaluation significantly boosts growth while overvaluation alters it. This impact seems to be stronger for developing countries. Rapetti et al. (2012) follow Rodrik's (2008) framework and estimate the impact of exchange rate undervaluation on economic growth for a large sample of countries ${ }^{5}$. They use different criteria, compared to Rodrik (2008), to differentiate between developed and developing countries. They find that the positive impact of undervaluation on growth, although sensitive to the criterion used, is sizable for both very poor and middle-income countries.

Later, some empirical findings, based on smooth transition regression models, supported the power of undervaluation in spurring growth. Among others, Béreau et al. (2012) analyse the impact of exchange rate misalignment on economic growth using a sample of industrialised and emerging economies between 1980 and 2007. The EER is built following the BEER and using the terms of

\footnotetext{
${ }^{3}$ The fundamental can be de-trended, referring to the long-run EER concept, or not, which relates to the mediumrun concept.

${ }^{4}$ In its original formulation, the Washington Consensus refers to a set of ten policies prescribed by Williamson as desirable for Latin American countries. Later on, it became a set of economic policies advocated for developing countries by international financial institutions such as the World Bank and IMF (Williamson, 2004).

${ }^{5}$ Rapetti et al. (2012) use the same sample than Rodrik (2008).
} 
trade, the relative productivity and the NFA as determinants. They find, using a PSTR specification, that small overvaluations and undervaluations boost economic growth while large overvaluations hinder it. Using a set of emerging and developed countries, Couharde and Sallenave (2013) investigate the impact of misalignments on economic growth based on a PSTR model. The equilibrium exchange rates are constructed using the parsimonious model of Alberola et al. (1999) and cointegration techniques. The results indicate that undervalued currencies spur economic growth up to a threshold. Beyond that, there is a reversal. The threshold is higher for Asian countries supporting their use of undervaluation as a strategy to boost growth. Despite these findings, no analysis, to the best of our knowledge; has attempted to address the issue of cross-sectional dependence. Besides, no attempt in testing granger causality between these variables in a nonlinear framework has been conducted.

This article analyses the long-run relationship between exchange rates misalignment and economic growth for a sample of homogeneous emerging economies using a panel smooth transition vector error correction model (PSTRVEC) from 1970 to 2014. Our index of undervaluation is computed using the BEER instead of the common PPP-based measures as estimated by Rodrik (2008). Two reasons justify this choice. First, the PPP-based measures approach is relevant only in the very long-run (Rogoff, 1996) and does not provide insights of exchange rate adjustments that would be consistent with world imbalances being unravelled (Berg and Miao, 2010). Our contribution to the topic is twofold. First, we use both linear and nonlinear cointegration tests and estimate the error correction model using an estimator that is robust to cross-sectional dependence and does not suffer from endogeneity, an issue overlooked in most nonlinear articles. Second, we test for granger causality between misalignment and economic growth in a nonlinear framework. We find that misalignment and economic growth are nonlinearly cointegrated. the PSTRVEC estimation results show that a rise in misalignment increases significantly output in the short-run when currencies are closer to equilibrium. When currencies are highly misaligned, the impact on growth is reduced. Output reverts slowly back to the long-run equilibrium following a deviation. No significant impact of output on misalignment was found in the short-run and the latter does not respond to deviation from equilibrium. We provide evidence that misalignment granger causes output at any given level of misalignment both in the short and long-run. A weaker granger causality was found between 
output and misalignment in the short-run when currencies are highly misaligned. This raises some important implications. Although emerging economies can use undervaluation as a growth strategy, the benefits are smaller the larger the undervaluation. A plausible explanation stems from the existence of large foreign currency denominated liabilities. This may hinder growth when currencies are largely undervalued. There is therefore an incentive to keep exchange rates closer to their equilibrium.

The rest of the paper is organized as follows. Section 2 presents the derivation of equilibrium exchange rate as in Alberola et al. (1999) and Alberola (2003). We follow the work of Ucar and Omay (2009); Omay et al. (2014) and explain the econometric framework in section 3. Section 4 focuses on the computation of the equilibrium real effective exchange rate (EREER) and the misalignment thereof while the empirical results are presented under section 5 . Section 6 presents the conclusion and policy recommendations.

\section{Equilibrium exchange rate derivation}

Following the work of Alberola et al. (1999) and Alberola (2003); and assuming that there are two countries in the world. Each country produces one tradable good (subscript $t$ ) and one non-tradable good (subscript $n t$ ). The real exchange rate $q$ can be defined as $q=e+p^{*}-p$ with $e$ being the nominal exchange rate expressed per unit of a foreign currency and $p^{*}$ and $p$ being respectively the price level in the foreign and domestic country ${ }^{6}$. These prices can be decomposed as $p=p_{t}+p_{n t}$ and $p^{*}=p_{t}^{*}+p_{n t}^{*}$ where $p_{n t}$ and $p_{t}$ are respectively the price of non-tradables and tradables goods. The real exchange $q$ can be written as:

$$
q=\left(e+p_{t}^{*}-p_{t}\right)-\left[(1-\beta)\left(p_{n t}-p_{t}\right)-(1-\beta)\left(p_{n t}^{*}-p_{t}^{*}\right)\right]
$$

The expression $\left(e+p_{t}^{*}-p_{t}\right)$ represents the relative price of domestic to foreign tradables while the remainder is the price of non-tradables relative to tradables across countries. The former plays the role of excess demand adjustment across sectors in the economy and the latter captures

\footnotetext{
${ }^{6}$ All the variables are in log form as in Taylor et al. (2001).
} 
the competitiveness of the economy and determines the evolution of NFA. Current account (CA) adjustments are made so that the exchange rate achieves the target of the NFA. The CA is defined as the sum of the trade balance and the net income of holding foreign assets; and written as:

$$
C A=-\alpha p r x
$$

with prx being the international relative price and the negative sign before the $\alpha$ representing the trade off between the relative price of goods and the consumption of domestic goods. We express the relationship between current account and capital account as:

$$
c a=\eta(F-f)+\mu\left(i-i^{*}\right)
$$

with $c a$ being the capital account and $F$ the NFA target. The interest rate differential $\left(i-i^{*}\right)$ reflects the anticipated depreciation of the real exchange rate. The internal equilibrium is given by:

$$
\operatorname{pri}=\rho\left(d_{n}-d_{n}^{*}\right)
$$

with $\rho$ being the speed of adjustment between the demand functions for domestic $\left(d_{n}\right)$ and international $\left(d_{n}^{*}\right)$ non-tradable goods. This leads to the following expression:

$$
\begin{aligned}
& d_{n}=-(1-\beta) t b-\theta\left[\left(p_{n t}-p_{t}\right)-(k+z)\right] \\
& d_{n}^{*}=-(1-\beta) t b-\theta\left[\left(p_{n t}^{*}-p_{t}^{*}\right)-\left(k^{*}+z^{*}\right)\right]
\end{aligned}
$$

where $k$ and $k^{*}$ are variables representing sectoral productivity differential, $\theta$ is the elasticity price demand; and $z$ and $z^{*}$ are relative demand shocks in the non-tradable sector. $-(1-\beta) t b$ states that the share of production, expressed in terms of its foreign counterpart of non-tradable, is equal to the trade balance. The second term of (5) and (6) represents the Balassa-Samuelson effect.

Given that at the steady state pri, prx and $f$ are constants, the equilibrium exchange rate can be written as:

$$
\bar{q}=p \bar{r} x+p \bar{r} i
$$


with the external price $p \bar{r} x$ given by $(1-\beta) r^{*} F+\frac{\left(k-k^{*}\right)+\left(z-z^{*}\right)}{2}$ and the internal relative price $\bar{p} i$ being $\frac{r^{*} F}{\mu}$. Therefore, the equilibrium exchange rate can further be written as:

$$
\tilde{q}=(1-\beta) r^{*} F+\frac{\left(k-k^{*}\right)+\left(z-z^{*}\right)}{2}+\frac{r^{*} F}{\mu} .
$$

From this last expression, there are two determinants of exchange rate: the NFA position and the productivity differential. The exchange rate is expected to appreciate when both variables increase. The next section develops the econometric framework.

\section{Econometric framework}

This article uses a panel smooth transition regression (PSTR) model to estimate a long-run relationship between exchange rate misalignment and economic growth. Omay et al. (2014) state several reasons for choosing a PSTR specification. First, it allows the estimation of nonlinearities that may exist between variables. Second, it allows for a smooth change between regimes while models such as the panel transition regression (PTR) and the markov regime switching model allow for abrupt changes that are only valid once all agents change their behaviour simultaneously in the same direction. Third, the PSTR model allows different types of nonlinearities and asymmetric dynamics depending on the type of the transition function. Finally, it allows the choice of the appropriate switching variable and the type of the transition function. We next provide a brief review of the nonlinear panel cointegration and causality tests ${ }^{7}$.

\subsection{Nonlinear panel cointegration}

We consider the following panel regression model:

$$
y_{i, t}=\alpha_{i}+\beta_{i} x_{i, t}+\mu_{i, t} \quad \text { for } \quad i=1, \ldots, N \quad \text { and } \quad t=1, . ., T
$$

\footnotetext{
${ }^{7}$ These estimators were developed in Ucar and Omay (2009); Omay et al. (2014). The following framework is from Omay et al. (2014). We thank the authors for making the codes available.
} 
where $y_{i, t}$ and $x_{i, t}$ denote the observable $I(1)$ variables, $\beta=\left(\beta_{1}, \ldots, \beta_{m}\right)$ are parameters to be estimated; $\mu_{i, t}$ is the error term. $y_{i, t}$ is a scalar, and $x_{i, t}=\left(x_{1, t}, x_{2, t}, \ldots, x_{m, t}\right)$ is an $(m \times 1)$ vector and finally $\alpha_{i}$ is the fixed effect heterogeneous intercept. We assume that an $(n \times 1)$ vector $z_{i, t}^{\prime}=\left(y_{i, t}, x_{i, t}^{\prime}\right)$ is generated as $z_{i, t}=z_{i, t-1}+\epsilon_{i, t}$; where $\epsilon_{i, t}$ are i.i.d. with mean zero, positive definite variance-covariance matrix $\Sigma$, and $E\left(\epsilon_{i, t}\right)^{s}<\infty$ for some $s>4$.

If the error term $\mu_{i, t}$ in regression (9) is stationary, then the vector $z_{i, t}$ is said to be cointegrated, and $\mu_{i, t}$ is called the equilibrium error (Engle and Granger, 1987). We assume that $\mu_{i, t}$ can be modelled using the following nonlinear model:

$$
\mu_{i, t}=\gamma_{i} \mu_{i, t-1}+\psi_{i} \mu_{i, t-1} F\left(\mu_{i, t} ; \theta_{i}\right)+\xi_{i, t}
$$

where $\xi_{i, t}$ is a zero mean error and $F\left(\mu_{i, t} ; \theta_{i}\right)$ is a smooth function of $\mu_{i, t}$. By imposing $F\left(\mu_{i, t} ; \theta_{i}\right)=0$ or $F\left(\mu_{i, t} ; \theta_{i}\right)=\gamma_{i} \mu_{i}^{\prime}$ where $\mu_{i}^{\prime}$ is a vector of level parameters, we obtain conventional linear cointegration equation (Kapetanios et al., 2006a). Following earlier literature on nonlinear cointegration such as Kapetanios et al. (2006a); Ucar and Omay (2009) and Maki (2010); we assume that the transition function $F\left(\mu_{i, t} ; \theta_{i}\right)$ is of the exponential form: ${ }^{8}$

$$
F\left(\mu_{i, t-1} ; \theta_{i}\right)=1-\exp \left\{-\theta_{i} \mu_{i, t-1}^{2}\right\}
$$

It is assumed that $\mu_{i, t}$ is a mean zero stochastic process and that $\theta_{i}>0$. The transition function $F\left(\mu_{i, t-1} ; \theta_{i}\right)$ is bounded between zero and one; and is symmetrically U-shaped around zero. The parameter $\theta_{i}$ determines the speed of the transition between the two extreme values of the transition function $F\left(\mu_{i, t-1} ; \theta_{i}\right)$. The exponential transition function allows for adjustments to the longrun equilibrium depending on the size of the disequilibrium. Substituting (11) in (10) and reparametrising the resultant equation, we obtain the following regression model:

$$
\Delta \mu_{i, t}=\psi_{i} \mu_{i, t-1}\left[1-\exp \left\{-\theta_{i} \mu_{i, t-1}^{2}\right\}\right]+\xi_{i, t},
$$

\footnotetext{
${ }^{8}$ As shown by Kapetanios et al. (2003a, 2006a), the second order logistic and exponential functions both give rise to the same auxiliary regression for testing cointegration.
} 
If $\theta_{i}>0$, then it determines the speed of mean reversion. If $\theta_{i} \geq 0$, this process may exhibit unit root or explosive behaviour for small values of $\mu_{i, t-1}^{2}$. However, if the deviations from the equilibrium are sufficiently large, for large values of $\mu_{i, t-1}^{2}$, it has stable dynamics, and as a result, is geometrically ergodic provided that $\varphi_{i}+\psi_{i}<0 .^{9}$

Imposing $\varphi_{i}=0$, implying that $\mu_{i, t}$ follows a unit root process in the middle regime; and further allowing for possible serial correlation of the error term in (12), we obtain the following regression:

$$
\Delta \mu_{i, t}=\psi_{i} \mu_{i, t-1}\left[1-\exp \left\{-\theta_{i} \mu_{i, t-1}^{2}\right\}\right]+\sum_{j=1}^{\rho_{1}} \rho_{i j} \mu_{i, t-j} \xi_{i, t}
$$

The test of cointegration can be based on the specific parameter $\theta_{i}$ which is zero under the null hypothesis of no cointegration and positive under the alternative. Direct testing of the null hypothesis is not feasible since $\psi_{i}$ is not identified under the null. Following Luukkonen et al. (1988), one may replace the transition function in (11) with its first order Taylor approximation under the null resulting in the following auxiliary regression model:

$$
\Delta \mu_{i, t}=\delta_{i} \mu_{i, t-1}^{3}+\sum_{j=1}^{\rho_{i}} \mu_{i, t-j}+e_{i, t}^{\prime}
$$

where $e_{i, t}$ comprises the original shocks $\xi_{i, t}$ in equation (13) as well as the error term resulting from Taylor approximation. Note that we allow for different lag order $\rho_{i}$ for each entity in regression equation (14). The null hypothesis of no cointegration and the alternative can be formulated as:

$$
\begin{aligned}
& H_{0}: \delta_{i}=0, \text { for all } i \text { (no cointegration); } \\
& H_{1}: \delta_{i}<0 \text {, for some } i \text { (nonlinear cointegration). }
\end{aligned}
$$

In empirical applications, the number of augmentation terms in the auxiliary regression (14) is chosen using any convenient lag selection method. Following Ucar and Omay (2009), the cointegration test can be constructed by standardising the average of individual cointegration test statistics

\footnotetext{
${ }^{9}$ See Kapetanios et al. (2003a); Ucar and Omay (2009) for ergodicity of such nonlinear processes
} 
across the whole panel. The cointegration test for the i-th individual is the $t$-statistic for testing $\delta_{i}=0$ as in Kapetanios et al. (2003a); Ucar and Omay (2009) in equation (14). It is defined by:

$$
t_{i, N L}=\frac{\Delta \mu_{i}^{\prime} M_{t} \mu_{i,-1}^{3}}{\hat{\sigma}_{i, N L}\left(\mu_{i,-1}^{\prime} M_{t} \mu_{i,-1}\right)^{\frac{3}{2}}}
$$

where $\delta_{i, N L}^{2}$ is the consistent estimator such that $\delta_{i, N L}^{2}=\Delta \mu_{i}^{\prime} M_{t} \mu_{i} /(T-1) ; M_{t}=I_{T}-\tau_{T}\left(\tau_{T}^{\prime} \tau_{T}\right)^{-1} \tau_{T}^{\prime}$ with $\Delta \mu_{t}=\left(\Delta \mu_{i, 1}, \ldots, \Delta \mu_{i, T}\right)^{\prime}$ and $\tau_{T}=(1,1, \ldots, 1)$. Furthermore, when the invariance property and the existence of moments are satisfied, the usual normalization of $\bar{t}_{N L}$ statistic is obtained as follows:

$$
\bar{Z}_{N L}=\frac{\sqrt{N}\left(\bar{t}_{N L}-E\left(t_{i, N L}\right)\right)}{\sqrt{\operatorname{var}\left(t_{i, N L}\right)}} ;
$$

where $\bar{t}_{N L}=N^{-1} \sum_{i=1}^{N} t_{i, N L}$ and $\operatorname{Var}\left(t_{i, N L}\right)$ are respectively the expected value and variance of the $t_{i, N L}$ statistics given in (15).

Cross-sectional dependence is usually encountered in panel data. This may arise due to spatial correlations, spill-over effects, economic distance, omitted global variables and common unobserved shocks (see Omay and Kan (2010)). The presence of correlated errors through individuals makes the classical unit root and cointegration testing procedure invalid in panel data models. Banerjee et al. (2004) assess the finite sample performance of the available tests and find that all tests experience severe size distortions when panel members are cointegrated. Some tests, based on the regression equation including the unobserved and/or observed factors as the additional regressors, are suggested to overcome this issue. We can note the work of Moon and Perron (2004); Bai and Ng (2004); Pesaran (2007); Bai et al. (2009); Omay and Kan (2010); Kapetanios et al. (2003b, 2006b). Moreover, Maddala and Wu (1999); Chang (2004); Ucar and Omay (2009) consider the bootstrap based tests in order to obtain good properties. Therefore, the presence of cross-sectional dependence needs to be checked before the implementation of the testing procedure. Pesaran (2004) uses the following testing procedure:

$$
C D=\sqrt{\frac{2 T}{N(N-1)}}\left(\sum_{i=1}^{N-1} \sum_{j=i+1}^{N} \hat{\rho}_{i j}\right)
$$

where $\hat{\rho}_{i j}$ is the estimated correlation coefficient between error terms for the individuals $i$ and 
$j$. The sieve bootstrap method is applied to deal with cross-sectional dependence following the work of Ucar and Omay (2009). Once cointegration and long run relationship are established, the panel error correction model can be estimated. We follow Omay et al. (2014) and estimate a nonlinear panel smooth transition vector error correction (PSTRVEC) model to examine regime wise interaction between economic growth and exchange rates misalignment. This is justified by the fact that not only the adjustment to the long-run equilibrium level but also the dynamic interrelationship between the variables might be nonlinear.

\subsection{Specification of PSTRVEC}

Following the work of González et al. (2005) and Omay and Kan (2010), we consider the following PSTRVEC model ${ }^{10}$ :

$$
\begin{aligned}
\Delta g d p_{i, t} & =\mu_{1}+\beta_{1} e c_{i, t-1}+\sum_{j=1}^{p_{i}} \theta_{1 j} \Delta g d p_{i, t-j}+\sum_{j=1}^{q_{i}} \vartheta_{1 j} \Delta \operatorname{misal}_{i, t-j} \\
& +G\left(s_{i, t-1} ; \gamma, c\right)\left[\tilde{\beta}_{1} e c_{i, t-1}+\sum_{j=1}^{p_{i}} \tilde{\theta}_{1 j} \Delta g d p_{i, t-j}+\sum_{j=1}^{q_{i}} \tilde{\vartheta}_{1 j} \Delta m i s a l_{i, t-j}\right]+\xi_{1 i t}, \\
\Delta \operatorname{misal}_{i, t} & =\mu_{2}+\beta_{2} e c_{i, t-1}+\sum_{j=1}^{p_{i}} \theta_{2 j} \Delta g d p_{i, t-j}+\sum_{j=1}^{q_{i}} \vartheta_{2 j} \Delta m i s a l_{i, t-j} \\
& +G\left(s_{i, t-1} ; \gamma, c\right)\left[\tilde{\beta}_{2} e c_{i, t-1}+\sum_{j=1}^{p_{i}} \tilde{\theta}_{2 j} \Delta g d p_{i, t-j}+\sum_{j=1}^{q_{i}} \tilde{\vartheta}_{2 j} \Delta \text { misal }_{i, t-j}\right]+\xi_{2 i t}
\end{aligned}
$$

for $i=1, \ldots, N$ and $t=1, \ldots, T$; where $N$ and $T$ denote the cross-section and time dimensions of the panel respectively. $g d p_{i, t}$ denotes the gross domestic product per capita, misal $l_{i, t}$ denotes the exchange rate misalignment, $\mu_{i}$ represents the individual fixed effects, $e c_{i, t-1}$ is the lagged estimated error correction from regression (9) and $\xi_{i t}$ is the error term that is assumed to be a martingale difference with respect to the history of the vector $z_{i, t}=\left(g d p_{i, t}, \text { misal }_{i, t}\right)^{\prime}$ up to time $t$ 1 ; that is $E\left[\xi_{i t} \mid z_{i, t-1}, z_{i, t-2}, \ldots, z_{i, t-p}, \ldots\right]=0$, and that the conditional variance of the error term is constant, i.e, $E\left[\xi_{i t}^{2} \mid z_{i, t-1}, z_{i, t-2}, \ldots, z_{i, t-p}, \ldots\right]=\sigma^{2}$. We allow here for contemporaneous correlation across the errors of the $N$ equations (i.e., $\operatorname{cov}\left(\xi_{l i t}, \xi_{l j t}\right) \neq 0$ for $l=1,2$ and $i \neq j$ ).

\footnotetext{
${ }^{10}$ Another alternative method is the Bayesian regime-switching cointegration of Jochmann and Koop (2015).
} 
We consider the following logistic transition function for the time series STAR models as in González et al. (2005) and Omay and Kan (2010):

$$
G\left(s_{i, t-1} ; \gamma, c\right)=\left[1+\exp \left\{-\gamma \prod_{j=1}^{m}\left(s_{i, t-1}-c_{j}\right)\right\}\right]^{-1} \quad \text { with } \gamma>0 \text { and } c_{m} \geq \ldots \geq c_{1} \geq c_{0}
$$

where $c=\left(c_{1}, \ldots, c_{m}\right)^{\prime}$ is an $m$-dimensional vector of location parameters and the slope parameter $\gamma$ denotes the smoothness of the transition between the regimes. If $m=1$, we have a first-order logistic transition function and the extreme regimes correspond to low and high values of $s_{i t}$, so that the coefficients in equation (18) change smoothly from $\beta_{j}, \theta_{j}$ and $\vartheta_{j}$ to $\beta_{j}+\tilde{\beta}_{j}, \theta_{j}+\tilde{\theta}_{j}$ and $\vartheta_{j}+\tilde{\vartheta}_{j}$, respectively as $s_{i, t}$ increases. When $\gamma \rightarrow \infty$, the transition function $G\left(s_{i, t} ; \gamma, c\right)$ becomes an indicator function $I[A]$, which takes a value of 1 when event $\mathrm{A}$ occurs and 0 otherwise. The PSTR model reduces to the two regime of Hansen (1999b).

For $m=2, G\left(s_{i, t} ; \gamma, c\right)$ takes a value of 1 for both low and high $s_{i, t}$, minimizing at $\frac{c_{1}+c_{2}}{2}$. In that case, if $\gamma \rightarrow \infty$, the PSTR model reduces into a panel three-regime threshold regression model. If $\gamma \rightarrow 0$, the transition function will reduce into a constant and the PSTR model will collapse to a linear panel regression model for any value of $m$.

Following González et al. (2005), Omay and Kan (2010) and Omay et al. (2014); the specification procedure to estimate a PSTR consists of the following steps:

1. Specify an appropriate linear panel model for the data under investigation.

2. Test the null hypothesis of linearity against the alternative of smooth transition type nonlinearity. If linearity is rejected, select the appropriate transition variable $s_{i, t}$ and the form of the transition function.

3. Estimate the parameters in the selected PSTRVEC model.

There are nuisance parameters only identified under the null which render linearity tests and inference difficult (Hansen, 1999a,b; Omay et al., 2014). The null hypothesis of linearity can be expressed in different ways. Besides the equality of the parameters in the two regimes that can be specified as $H_{0}: \beta_{j}=\tilde{\beta}_{j}$ and $\theta_{j}=\tilde{\theta}_{j}$, a specification such as $H_{0}^{\prime}: \gamma=0$ also gives rise to a 
linear model (Omay et al., 2014). To overcome this problem, Luukkonen et al. (1988) recommend replacing the transition function $G\left(s_{i, t} ; \gamma, c\right)$ with an appropriate Taylor approximation. A $k^{\text {th }}$ order Taylor approximation for the first-order logistic transition function around $\gamma=0$ results in the following auxiliary regression:

$$
\Delta z_{i, t}=\lambda_{i}+\pi_{0}^{\prime} e c_{i, t-1}+\sum_{j=1}^{p_{i}} \psi_{o j} \Delta z_{i, t-j}+\sum_{h=1}^{k} \tilde{\pi}_{h}^{\prime} s_{i, t}^{h} e c_{i, t-1}+\sum_{h=1}^{k} \sum_{j=1}^{p_{i}} \tilde{\psi}_{h j} s_{i, t}^{h} \Delta z_{i, t-j}+e_{i, t}
$$

where $z_{i, t}=\left(g d p_{i, t}, \text { misal }_{i, t}\right)^{\prime}$ and $\lambda, \pi^{\prime}, \vartheta, \tilde{\pi}$, and $\tilde{\vartheta}$ are functions of $\mu_{i}, \beta, \theta_{j}, \vartheta_{j}, \tilde{\beta}_{,}, \tilde{\theta}_{j}, \tilde{\vartheta}_{j}, \gamma$, and $c_{i}$; and $e_{i, t}$ comprises the original disturbance terms $\xi_{i t}$ as well as the error term arising from the Taylor approximation. Testing $H_{0}: \gamma=0$ in (18) is equivalent to testing the null hypothesis $H_{0}: \omega_{1}=\omega_{2}=\omega_{3}$ where $\omega_{i} \equiv\left(\tilde{\pi}_{i}, \tilde{\psi}_{i}\right)$ in $(20)$. This test can be done by an $L M$-type test that approximates a $F$-distribution and defined as:

$$
L M=\frac{\left(S S R_{0}-S S R_{1}\right) / k p}{S S R_{0} /(T N-N-k(p+1))} \sim F(k p, T N-N-k(p+1)) ;
$$

Besides, Colletaz et al. (2006) propose a pseudo- $L R T$ statistic defined as:

$$
L R T=-2\left[\log \left(S S R_{1}\right)-\log \left(S S R_{0}\right)\right]
$$

where $S S R_{0}$ and $S S R_{1}$ are the sum of squared residuals under the null and alternative hypotheses respectively. The $L M$-statistic can be computed for several candidates in order to choose for an appropriate threshold variable $s_{i, t}$, and the one for which the $p$-value of the test statistic is the smallest can be selected.

The next step in the specification of a PSTR model is to choose between $m=1$ and $m=2$. Teräsvirta (1994) recommends using a decision rule based on a sequence of tests in equation (20). This test sequence is as follows. Using the auxiliary regression (20) with $k=3$, test the null hypothesis $H_{0}: \omega_{1}=\omega_{2}=\omega_{3}=0$. If it is rejected, test $H_{03}^{*}: \omega_{3}=0$, then $H_{02}^{*}: \omega_{2}=0 \mid \omega_{3}=0$ and $H_{01}^{*}: \omega_{1}=0 \mid \omega_{1}=\omega_{3}=0$. These hypotheses are tested by ordinary $F$-tests denoted as $F 3, F 2$ and $F 1$ respectively. If the $p$-value corresponding to $F 2$ is the smallest, then the exponential function should be selected while in all other cases, a first order logistic function should be preferred. 


\subsection{Estimation of the PSTRVEC and regime wise granger causality}

Once the transition variable and form of the transition function are selected, the PSTRVEC model can be estimated using a conventional nonlinear least squares estimator. A choice of initial values are needed in order to disburden the optimization algorithm. These values of $\gamma$ and $c$ are those that minimize the panel sum of squared residuals following a two-dimensional grid search procedure. For fixed values of the parameters in the transition function, $\gamma$ and $c$, the PSTRVEC model is linear in

parameters $\mu_{i}, \beta, \theta_{j}, \vartheta_{j}, \tilde{\beta}, \tilde{\theta}_{j}, \tilde{\vartheta}_{j}$; and therefore can be estimated using least squares.

The problem of cross-sectional dependence is usually encountered while using panel data. In equation (18), we have allowed for contemporaneous correlation across the errors of the equations in the system (i.e., $\operatorname{cov}\left(\xi_{l i t}, \xi_{l j t}\right) \neq 0$ for $l=1,2$ and $i \neq j$ ). As our sample comprises only emerging economies, we are likely to have strong serial correlation between panels. To resolve the crosssectional dependence issue, we follow Omay et al. (2014) and solve the growth and misalignment equations for all sample countries simultaneously using nonlinear Generalized Least Squares (GLS) estimator iteratively. By the same token, we remedy the problem of endogeneity bias.

The granger causality test can be conducted separately for each regime as in Li (2006) and Omay et al. (2014). Let a transition variable such as the growth rate of misalignment and a first order logistic transition function being selected, the null hypotheses of no granger causality can be formulated for low growth and high growth as follows: 
Table 1: Tests of granger causality

\begin{tabular}{|c|c|}
\hline $\begin{array}{l}\text { Misalignment does not granger cause output growth rate in low growth period } \\
\text { (i.e. when misalignment growth is less than some threshold value) in the short- } \\
\text { run }\end{array}$ & $H_{0}: \vartheta_{1}=0$ \\
\hline $\begin{array}{l}\text { Misalignment does not granger cause output growth rate in low growth period } \\
\text { (i.e. when misalignment growth is less than some threshold value) in the long- } \\
\text { run }\end{array}$ & $H_{0}: \beta_{1}=0$ and $/$ or $H_{0}: \beta_{1}=\vartheta_{1}=0$ \\
\hline $\begin{array}{l}\text { Misalignment does not granger cause output growth rate in high growth period } \\
\text { (i.e. when misalignment growth is greater than some threshold value) in the } \\
\text { short-run }\end{array}$ & $H_{0}: \vartheta_{1}=\tilde{\vartheta}_{1}=0$ \\
\hline $\begin{array}{l}\text { Misalignment does not granger cause output growth rate in high growth period } \\
\text { (i.e. when misalignment growth is greater than some threshold value) in the } \\
\text { long-run }\end{array}$ & $H_{0}: \beta_{1}=\tilde{\beta}_{1}=0$ and $/$ or $H_{0}: \beta_{1}=\tilde{\beta}_{1}=\vartheta_{1}=\tilde{\vartheta}_{1}=0$ \\
\hline $\begin{array}{l}\text { Output growth does not granger cause misalignment in low growth period (i.e. } \\
\text { when misalignment growth is less than some threshold) in the short-run }\end{array}$ & $H_{0}: \theta_{2}=0$ \\
\hline $\begin{array}{l}\text { Output growth does not granger cause misalignment in low growth period (i.e. } \\
\text { when misalignment growth is less than some threshold) in the long run }\end{array}$ & $H_{0}: \beta_{2}=0$ and/or $H_{0}: \beta_{2}=\theta_{2}=0$ \\
\hline $\begin{array}{l}\text { Output growth does not granger cause misalignment in high growth period (i.e. } \\
\text { when misalignment growth is greater than some threshold) in the short-run }\end{array}$ & $H_{0}: \theta_{2}=\tilde{\theta}_{2}=0$ \\
\hline $\begin{array}{l}\text { Output growth does not granger cause misalignment in high growth period (i.e. } \\
\text { when misalignment growth is greater than some threshold) in the long-run }\end{array}$ & $H_{0}: \beta_{2}=\tilde{\beta}_{2}=0$ and $/$ or $H_{0}: \beta_{2}=\tilde{\beta}_{2}=\theta_{2}=\tilde{\theta}_{2}=0$ \\
\hline
\end{tabular}

\section{Computation of equilibrium exchange rate and misalignment}

We start by computing the EREER and the misalignment index thereof for our sample of 14 emerging economies using annual data from 1970 to 2014. The sample comprises Argentina, Brazil, China, Egypt, India, Indonesia, Malaysia, Mexico, Morocco, Pakistan, Philippines, South Africa, Thailand and Turkey. These countries were chosen based on the Standard \& Poor Dow Jones country classification ${ }^{11}$. We use the parsimonious model of Alberola et al. (1999) and Alberola (2003); and estimate the long-run relationship between REER, relative productivity (RPROD) and the NFA which are the two fundamentals. The REER is computed as a weighted average of bilateral exchange rate against the top 10 trading partners based on the following expression:

$$
R E E R_{i t}=\frac{C P I_{i t} S_{i t}}{\prod_{j \neq i}^{N}\left(C P I_{j t} S_{j t}\right)^{w_{i j}}} ;
$$

\footnotetext{
${ }^{11}$ Due to data availability Czech Republic, Chile, Colombia, Poland, Taiwan, Peru, Russia and the United Arab Emirates were not included.
} 
where $N$ is the number of countries, $S_{j t}$ (respectively $S_{i t}$ ) is currency $J$ (respectively $i$ )'s bilateral exchange rate defined as the price of domestic currency in terms of foreign currency. $C P I_{j t}$ (respectively $C P I_{i t}$ ) is country $j$ (respectively $i$ )'s consumer price index $(\mathrm{CPI})$. $w_{i j}$, which measures the importance of country $j$ into country $i$ trade, are trade weights. They are computed as the sum of exports and imports of country $j$ with country $i$ over the global volume of imports and exports of country $i$ for the period under study. These weights are given by the below expression:

$$
w_{i j}=\frac{(X+M)_{i j}}{(X+M)_{i}}
$$

where $X_{i}$ and $M_{i}$ represent respectively the exports and imports of country $i$. Our proxy of RPROD is computed following Alberola et al. (1999); Couharde and Sallenave (2013) and is given by the expression:

$$
R P R O D_{i t}=\frac{C P I_{i t} P P I_{i t}}{\prod_{j \neq i}^{N}\left(C P I_{j t} P P I_{j t}\right)^{w_{i j}}} ;
$$

where $P P I_{j t}$ (respectively $P P I_{i t}$ ) is country $j$ (respectively $i$ )'s producer price index $(\mathrm{PPI}), w_{i j}$ are the same weights from (23) and CPI is defined as above. Bénassy-Quéré et al. (2009) explains that CPI contains more non-tradable goods than PPI which does not include services, making this ratio an acceptable proxy for tradable goods prices. All the variables used in this point are from the World Bank development indicators except the NFA data which are from the updated and extended version of the External Wealth of Nations Mark II ${ }^{12}$.

The long-run relationship is estimated using the Mean Group Autoregressive distributed lag (ARDL) of Pesaran and Smith (1995) up to three lags. All the variables are in log form except the NFA which is in percentage of GDP. The results are provided under table 2. As predicted by Alberola et al. (1999), a NFA' increase tends to appreciate significantly the exchange rate. However, RPROD is not correctly signed as it predicts a significant exchange rate depreciation following an increase. Discussing the sign on RPROD is not the focus of this article. However, Schnatz et al. (2003); Kamar and Ben Naceur (2007) state that its impact cannot be determined a priori, especially when this ratio does not measure correctly tradable prices. The speed of adjustment is negative and

\footnotetext{
${ }^{12}$ China's CPI was proxied by the GDP deflator. Various missing observations on the PPI were filled using inflation rates from the GDP deflator. The NFA are updated from 2011 using the current account balance growth rate computed using data from the World Bank Development Indicators.
} 
significant although higher under the ARDL with 2 and 3 lags, predicting around $90 \%$ of correction per annum.

Table 2: Long run estimates of REER

\begin{tabular}{lrrr}
\hline Variables & ARDL-1 & ARDL-2 & ARDL-3 \\
\cline { 2 - 4 } & Estimate & Estimate & Estimate \\
\hline RPROD & $0.687^{*}$ & $0.925^{* * *}$ & $0.984^{* * *}$ \\
NFA & $-0.0125^{* *}$ & $-0.00582^{* * *}$ & $-0.0101^{* *}$ \\
Speed of adj. & $-0.150^{* * *}$ & $-0.879^{* * *}$ & $-0.898^{* * *}$ \\
\hline
\end{tabular}

All tests based on MG. ${ }^{* * *},{ }^{* * *}$ correspond to a significance at $10 \%, 5 \%$ and $1 \%$.

We next compute the EREER and misalignment using the ARDL-2 as both variables are highly significant under this specification. Following Kamar and Ben Naceur (2007), the fundamentals are first decomposed into permanent $\tilde{F}$ and cyclical $(F-\tilde{F})$ components using the Hodrick-Prescott (HP) filter. Then the EREER is given by $\log \tilde{e}_{t}=\bar{\alpha}+\hat{\beta}_{t}^{\prime} \tilde{F}_{t}$; where $\hat{\beta}^{\prime}$ are the coefficients from the long-run regression and $\bar{\alpha}$ represents the specificity of each country but only when significant. The index of misalignment is constructed using the Elbadawi et al. (2009) approach as expressed by the following equations:

$$
\begin{aligned}
e_{t} & =\hat{\beta}^{\prime} F_{t}+\epsilon_{t} ; \\
\tilde{e}_{t} & =\bar{e}+\hat{\beta}^{\prime}\left(\tilde{F}_{t}-\overline{\tilde{F}}_{t}\right) ; \\
\operatorname{Misal}_{t} & =e_{t}-\tilde{e}_{t} ;
\end{aligned}
$$

where the bar over a variable represents the mean for that variable, $\beta$ represents the long-run estimates and intercepts if significant; and $\tilde{e}_{t}$ is the EREER. The intuition behind the Elbadawi et al. (2009) approach is to normalize the EREER so that misalignment index is set to zero and no currency can be overvalued or undervalued for the whole period under study. Graph 1 in the appendix presents the misalignment computed. We can note that most countries have managed to reduce their misalignment post 2000. Since the 2007 financial crisis, many of those countries are maintaining undervalued currencies with few exceptions such as Brazil and Turkey. The next section presents the empirical results. 


\section{Empirical results}

Before estimating the relationship between exchange rate misalignment and economic growth, we test for the presence of unit root in these variables. The real gross domestic product per capita (GDP) was obtained from the World Bank development indicators. The unit root tests are based on the linear IPS test of Im et al. (2003) and the nonlinear UO test of Ucar and Omay (2009). The results are provided in table 3 .

Table 3: Linear and nonlinear panel unit roots

\begin{tabular}{|c|c|c|c|c|c|c|c|c|}
\hline \multirow[t]{3}{*}{ Variables } & \multicolumn{4}{|c|}{ IPS test } & \multicolumn{4}{|c|}{ UO test } \\
\hline & \multicolumn{2}{|c|}{ Intercept } & \multicolumn{2}{|c|}{ Intercept \& trend } & \multicolumn{2}{|c|}{ Intercept } & \multicolumn{2}{|c|}{ Intercept \& trend } \\
\hline & $W$-stat & $t$-stat & $W$-stat & $t$-stat & $W$-stat & $t$-stat & $W$-stat & $t$-stat \\
\hline Gdp & 5.478 & -0.312 & 1.970 & -1.819 & 5.635 & -0.348 & $1.959^{*}$ & $-1.763^{*}$ \\
\hline misal & 0.278 & -1.471 & 0.251 & -2.157 & -0.363 & -1.712 & $-1.177^{* * *}$ & $-2.395^{* * *}$ \\
\hline
\end{tabular}

The results of the linear and the nonlinear tests with intercept suggest that both our variables contain a unit root. However, according to the nonlinear test with intercept and trend, the variables seem trend stationary. Omay et al. (2014) stress that conventional linear tests may have low power and size properties against nonlinear processes. Besides, the plot of our misalignment index does not indicate the presence of a trend. We therefore treat all variables as $I(1)$ and test for cointegration. Before, we estimate panel models with fixed effects. The results are presented below with the $t$-statistics in parentheses.

$$
\begin{aligned}
g d p_{i, t} & =\underset{(7.36)}{0.118 \text { misal }_{i, t}} \\
\text { misal }_{i, t} & =\underset{(7.36)}{0.687 g d p_{i, t}}
\end{aligned}
$$

In both regressions, misalignment and output are positive and significant. We extract the residuals in order to test for linear and nonlinear cointegration. We first perform the Pesaran (2004) crosssectional dependence (CD) test on the residuals and find, with a test statistic of 42.85 and a 
$p$-value of 0.00 , the presence of cross-sectional dependence. Given this result, we use the bootstrap technique in order to compute the $p$-values of the cointegration tests. The linear test is based on the Pedroni (1999) cointegration test and the nonlinear test is based on equation (16). Table 4 provides the different results.

Table 4: Linear and nonlinear cointegration tests

\begin{tabular}{|c|c|c|c|c|}
\hline \multirow[t]{2}{*}{ Model } & \multicolumn{2}{|c|}{ Linear test } & \multicolumn{2}{|c|}{ Nonlinear test } \\
\hline & $W$-stat & $t$-stat & $W$-stat & $t$-stat \\
\hline$\hat{u}_{i, t}=G d p_{i, t}-X_{i, t} \beta$ & 1.759 & -1.141 & $0.885^{* *}$ & $-1.429^{* *}$ \\
\hline$\hat{u}_{i, t}=$ Misal $_{i, t}-X_{i, t} \beta$ & $-1.029^{* *}$ & $-1.762^{* *}$ & $-0.943^{* *}$ & $-1.844^{* *}$ \\
\hline
\end{tabular}

The linear test rejects the null of no cointegration only under model 2. However, for the nonlinear test, our index of misalignment and output are cointegrated. As this cointegrating relationship may be nonlinear, we proceed in estimating a nonlinear panel model.

The first step is to estimate a linear panel vector error-correction model (PVEC) and conduct a test of linearity. The PVEC model provides the following results:

$$
\begin{gathered}
\Delta g d p_{i, t}=\mu_{1}-\underset{(-1.45)}{0.005} e c_{i, t-1}+\underset{(5.14)}{0.209 \Delta g d p_{i, t-1}}+\underset{(1.70)}{0.003 \Delta m i s a l_{i, t-1}} \\
\Delta m i s a l_{i, t}=\mu_{2}+\underset{(3.73)}{0.317 e c_{i, t-1}}-\underset{(-0.91)}{0.037} \mathrm{misal}_{i, t-1}-\underset{(-2.57)}{2.362} \Delta g d p_{i, t-1}
\end{gathered}
$$

The error correction term is negative but not significant in the output equation while it is significant but positive in the misalignment equation. Looking at the growth equation, an increase in undervaluation has a significant positive impact on growth in the short-run. In the misalignment equation, an increase in growth tends to reduce undervaluation in the short-run. The next step is to test the linear PVEC model for linearity. This is conducted separately for both equations. We use the misalignment growth, output growth and the error-correction as transition variables. If misalignment growth is selected as the appropriate transition variable, then nonlinearities between output growth and misalignment are explained by the rate of change of misalignment. If output growth is selected then nonlinearities are explained by business cycle phases. If it is the 
error correction term, then deviations from equilibrium are responsible for the nonlinearities. The appropriate transition variable is selected as the one that strongly reject linearity. Table 5 presents the results.

Table 5: Linearity tests

\begin{tabular}{lccc}
\hline & & \multicolumn{2}{c}{ Transition variables } \\
\cline { 2 - 4 } Model & \multicolumn{1}{c}{$\Delta$ Fisal $_{i, t-2}$} & $\Delta g d p_{i, t-2}$ & ect $t_{i, t-2}$ \\
\cline { 2 - 4 } & F-test & F-test & F-test \\
\hline Gdp & $2.882^{* *}$ & $2.636^{* *}$ & 1.354 \\
Misal. & $22.035^{* * *}$ & $8.306^{* * *}$ & $21.685^{* * *}$ \\
\hline
\end{tabular}

Test of linearity against a PSTR specification. ${ }^{* * *},{ }^{* *}$ denote significance at $1 \%$ and $5 \%$.

We can note that the null hypothesis of linearity is rejected when misalignment and output growth are used as the transition variables. However, when the error correction term is used as the transition variable, linearity is rejected only under the misalignment equation. The strongest rejection is obtained when misalignments growth are used as the candidate transition variable. We therefore select it as the appropriate transition variable and proceed in the determination of the form of the transition function. The different F-tests based on equation (20) are provided in table 6. Let recall that the test selects $m=2$ when $F_{2}$ records the strongest rejection of the null and $m=1$ for other alternatives.

Table 6: Choice of transition

\begin{tabular}{|c|c|c|c|}
\hline & $F_{1}$ & $F_{2}$ & $F_{3}$ \\
\hline & F-test & F-test & F-test \\
\hline Gdp & $2.882^{* *}$ & 1.897 & 1.952 \\
\hline Misal. & $22.035^{* * *}$ & $16.55^{* *}$ & $24.253^{* * *}$ \\
\hline
\end{tabular}

From the results, the strongest rejection occurs for $F_{1}$ for the output regression and for $F_{3}$ for the misalignments regression. We therefore conclude that the logistic transition function is the appro- 
priate function and we have $m=1$, leading to one threshold and two regimes. We next estimate the PSTRVEC model using the nonlinear GLS iteratively in order to solve for possible cross-sectional dependence, providing the maximum likelihood estimates. To speed up the estimation process, good starting values for the slope of the transition function $(\gamma)$ and the threshold $(c)$ are obtained using a grid-search procedure. The results are as follows:

$$
\begin{aligned}
& \Delta g d p_{i, t}=\mu_{1}-\underset{(-3.594)}{0.061} e c_{i, t-1}+\underset{(3.371)}{0.242 \Delta g d p_{i, t-1}}+\underset{(5.520)}{0.020 \Delta \text { misal }_{i, t-1}} \\
& +\left[\underset{(2.884)}{0.059 e c_{i, t-1}}+\underset{(2.326)}{0.226} \Delta g d p_{i, t-1}-\underset{(-2.992)}{0.015} \Delta \text { misal }_{i, t-1}\right] \cdot G\left(s_{i, t-1} ; \gamma, c\right), \\
& \Delta \text { misal }_{i, t}=\mu_{2}+\underset{(1.122)}{0.110 e c_{i, t-1}}+\underset{(1.122)}{0.715 \Delta g d p_{i, t-1}}+\underset{(1.684)}{0.295 \Delta \operatorname{misal}_{i, t-1}} \\
& +\left[-\underset{(-0.870)}{0.091} e c_{i, t-1}-\underset{(-0.666)}{0.461} \Delta g d p_{i, t-1}+\underset{(0.263)}{\left.0.063 \Delta \text { misal }_{i, t-1}\right]} \cdot G\left(s_{i, t-1} ; \gamma, c\right)\right. \\
& G\left(\Delta \operatorname{misal}_{i, t-1} ; \gamma, c\right)=\left(1+\exp \left(\underset{-1.852}{-5.941}\left(\Delta \text { misal }_{i, t-1}+\underset{(-1.766)}{0.102}\right)\right)\right)^{-1}
\end{aligned}
$$

The speed of transition $\gamma$ is low and significant, indicating a smooth transition between extreme regimes. The threshold value $c$ is estimated at $-10.2 \%$. Regime I occurs whenever the growth rates of misalignment are lower than the threshold while regime II corresponds to higher growth rates. Given our index of misalignment and the sign on the threshold, regime I corresponds to a reduction of misalignment. In that sense, under regime I, the REER tends to revert back to the equilibrium. By the same token, under regime II, the REER is far away from the equilibrium, denoting increase level of misalignment. Looking at our estimates from the PSTRVEC and focusing first on the growth equation, the speed of adjustment is negative and significant under regime I. This implies that output reverts to long-run equilibrium after a deviation. The magnitude is however smaller, indicating only a $6 \%$ correction per annum. The coefficient of the lagged misalignment is positive and strongly significant. This implies that a $1 \%$ rise in misalignment increases growth by $0.02 \%$ in the short-run when there is a decrease in misalignment. For regime II, the speed of adjustment 
becomes $-0.002^{13}$. This implies a slower reversion of output to long-run equilibrium whenever exchange rates are highly misaligned. For the estimate on misalignment, the impact on growth is smaller but significant as a rise increases output by only $0.005 \%$ in the short-run. This predicts a decline in the effect of undervaluation on growth in regime of high misalignment.

We now focus on the misalignment equation. The speed of adjustment is positive but not significant, implying that misalignment does not respond to deviation from long-run equilibrium in regime I. The estimate on output is positive but not significant. Thus, a rise in output does not increase misalignment under regime I. The speed of adjustment remains positive (0.19) and not significant under regime II. Again, there is no adjustment to deviation from long-run equilibrium. Although positive $(0.715-0.461=0.254)$, the estimate on output still remains insignificant. A rise in output does not increase misalignment under regime II.

We now analyse the regime-wise granger causality results. As in Omay et al. (2014), the test is conducted by analysing the lagged explanatory variable for the short-run and by analysing the speed of adjustment for the long-run causality. The joint significance test of the error correction term and lagged explanatory variables is performed for the stronger form of granger causality. The various tests are conducted for regime I, $G\left(\Delta\right.$ misal $\left._{i, t-1} ; \gamma, c\right)=0$, and for regime II, $G\left(\Delta\right.$ misal $\left._{i, t-1} ; \gamma, c\right)=$ 1, separately. Table 7 summarizes the different results.

\footnotetext{
${ }^{13} \mathrm{As}-0.061+0.059=-0.002$.
} 
Table 7: Regime-wise causality tests

\begin{tabular}{|c|c|c|c|c|c|}
\hline \multirow{3}{*}{ Source of causation } & \multicolumn{5}{|c|}{ Dependent variable } \\
\hline & \multicolumn{2}{|c|}{$\triangle G D P$} & & \multicolumn{2}{|c|}{$\Delta$ Misal. } \\
\hline & low growth regime & high growth regime & & low growth regime & high growth regime \\
\hline \multicolumn{6}{|c|}{ Short-run } \\
\hline$\Delta$ Misal. & $30.47^{* * *}$ & $54.13^{* * *}$ & & & \\
\hline$\triangle G D P$ & & & & 1.26 & $4.72^{*}$ \\
\hline \multicolumn{6}{|c|}{ Long-run } \\
\hline ECT & $12.92^{* * *}$ & $16.29^{* * *}$ & & 1.25 & $8.86^{* *}$ \\
\hline \multicolumn{6}{|c|}{ Joint test (short and long-run) } \\
\hline$E C T / \Delta M i s a l$ & $45.55^{* * *}$ & & $105.81^{* * *}$ & & \\
\hline$E C T / \triangle G D P$ & & & & $4.72^{*}$ & $31.63^{* *}$ \\
\hline
\end{tabular}

The results of the short-run granger causality test imply that exchange rate misalignment granger causes output growth both in low and high growth regimes. The test is highly significant at $1 \%$. However, there is a statistical weak evidence of output granger causing misalignment in high growth regime. The null hypothesis of output not granger causing misalignment is rejected only at $10 \%$. Looking at the long-run results, we can note that our misalignment index granger causes output in both regimes. The null hypothesis is strongly rejected in both cases. On the other hand, output granger causes misalignment in the long-run only under regime II which corresponds to periods of large misalignment. The joint test which is a combination of the short and long-run tests suggest that misalignment significantly granger causes output in both regimes. We can therefore state that the primary effect of misalignment on growth are from the short-run effects. The joint test also indicates that output granger causes misalignment. Under regime I the evidence is statistically weak while it becomes fairly stronger under regime II stemming from the weak short-run causality.

How these results are related to the literature? Although the literature has not dealt with error correction model in a nonlinear framework, there are similarities. Indeed, Béreau et al. (2012) among others, find that small currencies overvaluations and undervaluations tend to boost growth. However, our findings show that the benefit tends to be smaller the larger the undervaluation. A plausible explanation stems from the existence of large foreign currency denominated liabilities. 
This may hinder growth when currencies are largely undervalued. Thus, exchange rates closer to equilibrium, as found in this article, will have a significant positive impact on economic growth. These results provide an incentive for countries to keep their exchange rates closer to equilibrium.

\section{Conclusion and policy recommendations}

The importance of exchange rate in an economy can be seen in the various policies implemented to manage its level and evolution on a daily basis. A large body of literature has analysed the impact of exchange rate, or its deviation from a certain equilibrium, on economic growth. We have just done that in this article for a sample of emerging economies using a panel smooth transition regression vector error correction model (PSTRVEC). This allows us to model the short and longrun impact of misalignment on growth in a nonlinear framework. We go a step further and provide a granger causality test. The misalignment index is constructed using the parsimonious model of Alberola et al. (1999) and Alberola (2003). We find that a PSTRVEC with two extreme regimes corresponding to periods of low and high misalignment better explains the model. An increase in misalignment significantly spurs output in the short-run when exchange rates are closer to equilibrium. However, when exchange rate misalignment is increasing, the impact on growth tends to become smaller. Besides, output reverts back to equilibrium faster when currencies are less misaligned. We find no significant increase in misalignment following a rise in output in the shortrun. There is also no tendency for misalignment to revert back to equilibrium following a deviation. The granger causality test was conducted separately for both extreme regimes. We find that, both in the short and long-run, misalignment significantly granger causes output in both regimes. However, output granger causes misalignment both in the short and long-run only when currencies are highly misaligned, although the evidence is weak for the former. Some policy implications can be drawn from the findings. The article provides evidence that undervaluation spurs growth both in the short and long-run. This explains the undervaluation strategy pursued by most East-Asian economies. However, we caution against increase level of misalignment. Indeed, when currencies

are highly undervalued, the impact on growth is smaller. A plausible explanation is the existence of large foreign currency denominated liabilities which may hinder growth when currencies are 
largely undervalued. Therefore there is an incentive for countries to keep their currencies closer to equilibrium or reduce their misalignment. 


\section{References}

Aguirre, A. and Calderón, C. (2005). Real exchange rate misalignments and economic performance. Documentos de Trabajo (Banco Central de Chile), (315):1-49.

Aizenman, J. and Lee, J. (2007). International reserves: precautionary versus mercantilist views, theory and evidence. Open Economies Review, 18(2):191-214.

Alberola, E. (2003). Misalignment, liabilities dollarization and exchange rate adjustment in latin america. Banco de España Research Paper No. WP-0309.

Alberola, E., Lopez, H., Ubide, A. J., and Cervero, S. G. (1999). Global equilibrium exchange rates: Euro, dollar,'ins','outs', and other major currencies in a panel cointegration framework. IMF Working Paper.

Bai, J., Kao, C., and Ng, S. (2009). Panel cointegration with global stochastic trends. Journal of Econometrics, 149(1):82-99.

Bai, J. and Ng, S. (2004). A panic attack on unit roots and cointegration. Econometrica, pages $1127-1177$.

Banerjee, A., Marcellino, M., and Osbat, C. (2004). Some cautions on the use of panel methods for integrated series of macroeconomic data. The Econometrics Journal, 7(2):322-340.

Bénassy-Quéré, A., Béreau, S., and Mignon, V. (2009). Robust estimations of equilibrium exchange rates within the g 20: A panel BEER approach. Scottish Journal of Political Economy, 56(5):608633.

Béreau, S., Villavicencio, A. L., and Mignon, V. (2012). Currency misalignments and growth: a new look using nonlinear panel data methods. Applied Economics, 44(27):3503-3511.

Berg, A. and Miao, Y. (2010). The real exchange rate and growth revisited: The washington consensus strikes back? IMF Working Papers, pages 1-24.

Chang, Y. (2004). Bootstrap unit root tests in panels with cross-sectional dependency. Journal of Econometrics, 120(2):263-293. 
Clark, P. and MacDonald, R. (1998). Exchange rates and economic fundamentals: A methodological comparison of BEERs and FEERs. IMF Working Paper, (67).

Colletaz, G., Hurlin, C., et al. (2006). Threshold effects of the public capital productivity: an international panel smooth transition approach. Document de Recherche du Laboratoire d' Economie d Orléans, 1.

Couharde, C. and Sallenave, A. (2013). How do currency misalignments threshold affect economic growth? Journal of Macroeconomics, 36:106-120.

Dooley, M. P., Folkerts-Landau, D., and Garber, P. (2003). An essay on the revived bretton woods system. Technical report, National Bureau of Economic Research.

Driver, R. L. and Westaway, P. F. (2005). Concepts of equilibrium exchange rates. Bank of England Publications Working Paper, (248).

Elbadawi, I., Kaltani, L., and Soto, R. (2009). Aid, real exchange rate misalignment and economic performance in sub-saharan africa. Available at SSRN 1526569.

Engle, R. F. and Granger, C. W. (1987). Co-integration and error correction: representation, estimation, and testing. Econometrica: Journal of the Econometric Society, pages 251-276.

González, A., Teräsvirta, T., and Dijk, D. v. (2005). Panel smooth transition regression models. Technical report, SSE/EFI Working Paper Series in Economics and Finance.

Hansen, B. (1999a). Testing for linearity. Journal of Economic Surveys, 13(5):551-576.

Hansen, B. E. (1999b). Threshold effects in non-dynamic panels: Estimation, testing, and inference. Journal of Econometrics, 93(2):345-368.

Im, K. S., Pesaran, M. H., and Shin, Y. (2003). Testing for unit roots in heterogeneous panels. Journal of Econometrics, 115(1):53-74.

Jochmann, M. and Koop, G. (2015). Regime-switching cointegration. Studies in Nonlinear Dynamics 8 Econometrics, 19(1):35-48.

Kamar, B. and Ben Naceur, S. (2007). Gcc monetary union and the degree of macroeconomic policy coordination. IMF Working Paper, pages 1-33. 
Kapetanios, G., Shin, Y., and Snell, A. (2003a). Testing for a unit root in the nonlinear star framework. Journal of Econometrics, 112(2):359-379.

Kapetanios, G., Shin, Y., and Snell, A. (2003b). Testing for a unit root in the nonlinear star framework. Journal of Econometrics, 112(2):359-379.

Kapetanios, G., Shin, Y., and Snell, A. (2006a). Testing for cointegration in nonlinear smooth transition error correction models. Econometric Theory, 22(02):279-303.

Kapetanios, G., Shin, Y., and Snell, A. (2006b). Testing for cointegration in nonlinear smooth transition error correction models. Econometric Theory, 22(02):279-303.

Li, J. (2006). Testing granger causality in the presence of threshold effects. International Journal of Forecasting, 22(4):771-780.

Luukkonen, R., Saikkonen, P., and Teräsvirta, T. (1988). Testing linearity against smooth transition autoregressive models. Biometrika, 75(3):491-499.

MacDonald, R. (1997). What determine real exchange rate? the long and short of it. Journal of International Financial Markets, Institutions and Money, (8):117-153.

Maddala, G. S. and Wu, S. (1999). A comparative study of unit root tests with panel data and a new simple test. Oxford Bulletin of Economics and Statistics, 61(S1):631-652.

Maki, D. (2010). An alternative procedure to test for cointegration in star models. Mathematics and Computers in Simulation, 80(5):999-1006.

Moon, H. R. and Perron, B. (2004). Testing for a unit root in panels with dynamic factors. Journal of Econometrics, 122(1):81-126.

Omay, T., Hasanov, M., and Ucar, N. (2014). Energy consumption and economic growth: evidence from nonlinear panel cointegration and causality tests. Applied Econometrics, 34(2).

Omay, T. and Kan, E. Ö. (2010). Re-examining the threshold effects in the inflation-growth nexus: Oecd evidence. Economic Modelling, 27(5):996-1005.

Pesaran, M. (2004). General diagnostic tests for cross section dependence in panels. 
Pesaran, M. H. (2007). A simple panel unit root test in the presence of cross-section dependence. Journal of Applied Econometrics, 22(2):265-312.

Pesaran, M. H. and Smith, R. (1995). Estimating long-run relationships from dynamic heterogeneous panels. Journal of Econometrics, 68(1):79-113.

Rapetti, M. (2013). The real exchange rate and economic growth: Some observations on the possible channels. Technical report, Working Paper, University of Massachusetts, Department of Economics.

Rapetti, M., Skott, P., and Razmi, A. (2012). The real exchange rate and economic growth: are developing countries different? International Review of Applied Economics, 26(6):735-753.

Rodrik, D. (2008). The real exchange rate and economic growth. Brookings Papers on Economic Activity, 2008(2):365-412.

Rogoff, K. (1996). The purchasing power parity puzzle. Journal of Economic Literature, 34(2):647668.

Schnatz, B., Vijselaar, F., and Osbat, C. (2003). Productivity and the ('synthetic') euro-dollar exchange rate.

Siregar, R. (2011). The concepts of equilibrium exchange rate: A survey of literature.

Taylor, M. P., Sarno, L., et al. (2001). Real exchange rate dynamics in transition economies: a nonlinear analysis. Studies in Nonlinear Dynamics $\&$ Econometrics, 5(3):153-177.

Teräsvirta, T. (1994). Specification, estimation, and evaluation of smooth transition autoregressive models. Journal of the American Statistical Association, 89(425):208-218.

Ucar, N. and Omay, T. (2009). Testing for unit root in nonlinear heterogeneous panels. Economic Letters, 104(1):5-8.

Williamson, J. (1994). Estimating equilibrium exchange rates.

Williamson, J. (2004). The Washington consensus as policy prescription for development. Development Challenges in the 1990s: Leading Policymakers Speak from Experience, pages 31-33. 


\section{Appendix}

Figure 1: Exchange rate misalignments

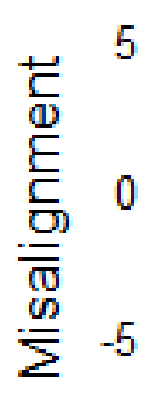

$-10$

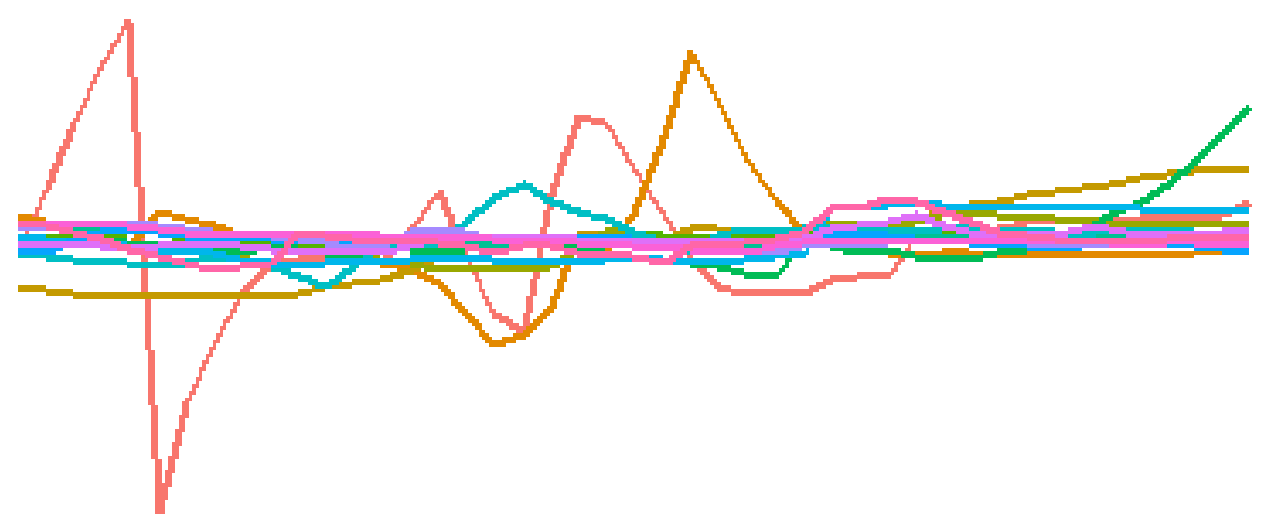

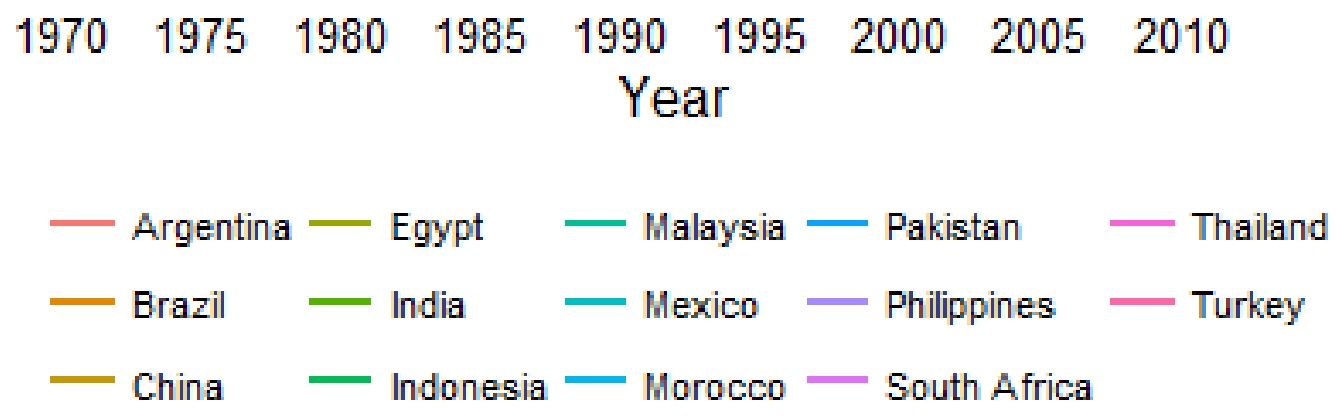

